\title{
Development and Evaluation of an Impedance Spectroscopy Sensor to Assess Cooking Oil Quality
}

\author{
A. Y. Khaled, S. A. Aziz, and F. Z. Rokhani
}

\begin{abstract}
When the cooking oil is used repeatedly, several unwanted substances are generated, which may cause health problems. This study was conducted to determine the possibility of using the impedance spectroscopy to differentiate among varying cooking oil quality at various intervals of heating time at constant temperature. The frequency has started from 100 Hz to $100 \mathrm{kHz}$. Fresh, 10-hour, 20-hour, 30-hour, and 40-hour heated cooking oil was prepared by using lab oven at temperature of $180 \mathrm{oC}$. In this study, a sensing probe was designed to measure the electrical properties of the oil samples. The oil samples were analyzed using a viscometer to measure the viscosity of the oil, a sensor to measure total polar compound (TPC), and an impedance probe connected to a LCR meter to measure the electrical properties of the oil. The measurements were analyzed and correlated with oil quality parameters obtained from a viscometer and a sensor of TPC. The discrimination between different heated hours of oil samples was examined and the results were compared to their physico-chemical properties such as viscosity and total polar compounds. The effect of heating of frying oils were successfully evaluated and discriminated using the impedance spectroscopy. Significant correlations $(r-\mathbf{- 0 . 9 8 4 7 2})$ were found between changes in total polar compound properties of oil and the impedance values.
\end{abstract}

Index Terms-Impedance, cooking oil, interdigitated sensor, total polar compound.

\section{INTRODUCTION}

Controlling quality of cooking oil becomes essential in fried food industries. During frying, various chemical processes occurred like hydrolysis, thermal oxidation, and polymerization. These occurred in the presence of water produced by food being fried, oxygen and high temperature, leading to decomposition of the food which badly affect the flavor and color [1]-[3]. In addition, using oil continuously or repeatedly without monitoring the quality may hazardous to human health [4]-[6].

Many criterias are been used to evaluate whether the oil can be used again or need to be discarded. These criteria can be divided into physical and chemical indicators. In homes,

Manuscript received August 10, 2013; revised October 10, 2013. This work was supported in part by the Prototype Research Grant Scheme, Ministry of Higher Education, project number 5528400, Development and Evaluation of an Impedance Spectroscopy Sensor to Assess Cooking Oil Quality.

A. Y. khaled is with Faculty of Engineering, Universiti Putra Malaysia (e-mail: f_yahya87@yahoo.co.in).

S. Abd Aziz was with Universiti Putra Malaysia. She is now the head department of Department of Biological \& Agricultural Engineering, MALAYSIA (e-mail: suzana@eng.upm.edu.my).

F. Z. Rokhani is with Computer and Communication System Department, Faculty of Engineering, Universiti Putra Malaysia, Malaysia (e-mail: fzd@eng.upm.edu.my). cafeterias, restaurants and food service, the indicator is the change in physical properties of the frying oil, such as too much smoke, the oil becomes dark, greased texture, and strong odor [7]. However, these changes may only manifest when the oil quality has already become unusable. On the other hand, chemical properties such as; free fatty acid (FFA) [8], total polar compounds (TPC) [9], index value (IV), and peroxide value (PV) of the frying oil [10] are the proper pointer for evaluating the oil quality during frying. In laboratories and industries, chemical test is been used to determine oil quality. However, it's time consuming, expensive and expertise is required to conduct the appraisal.

Several technical methods are used to assess oil quality such as image analysis to determine the total polar compound [11], column chromatography [12], and Fourier Transform Infrared (FTIR) [13], however, these methods are time consuming and laborious. Therefore, more fast and easy analytical method should be considered for evaluation cooking oil quality. In this study, we developed impedance sensor probe using impedance spectroscopy technique. The objective of this study is to develop and evaluate a sensing system to assess cooking oil quality. Specifically, this study was trying to correlate the impedance measurement of the heated oil with the TPC value at different frequency.

\section{MATERIALS AND Methods}

\section{A. Sample Preparation}

Palm oil was bought from local market and of good quality. The oil was divided into five samples of $150 \mathrm{ml}$ each; unheated, 10 hours heated, 20 hours heated, 30 hours heated, and 40 hours heated, as shown in Fig. 1.

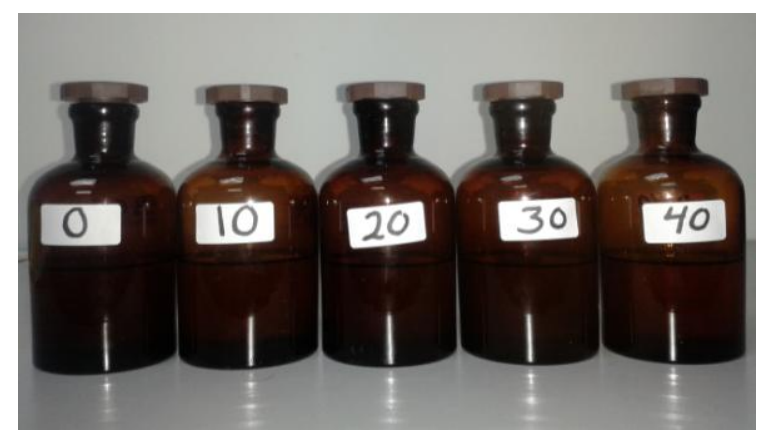

Fig. 1. Oil samples kept in the amber glass bottles.

The heating time of the five samples was ranges from 0 to 40 hours (10 hours interval for each sample) and was heated in an oven at $180 \pm 3^{\circ} \mathrm{C}$. All cooking oil samples were kept at $20^{\circ} \mathrm{C}$ until further analysis. These samples were used to evaluate the quality of the oil by knowing the change of 
impedance at different heating times.

\section{B. Impedance Sensing Probe Design}

The sensor used is the planar-interdigitated electrodes, between and around which the oil conductance is measured. The sensor was designed by using Traxmaker program. The sensor structure was designed with some variables, where $\mathrm{n}$ is referred to the number of electrode teeth, $d$ is a fixed separation distance between the teeth, $\mathrm{A}$ is the area which arranged in parallel, as shown in the Fig. 2 and $\epsilon_{r}$ is the relative permittivity of the dielectric material. This sensor configuration is referred to as two interdigitated electrodes. The bonding pads connect the interdigitated electrode with soldering wires area. This sensor was $20 \mathrm{~mm}$ by $10 \mathrm{~mm}$ in size with the interdigitated electrode structure patterned on one side of the copper foil. The back side of the PCB under the sensor electrodes had a solid layer of solder mask. This sensor had 30 electrode teeth. The electrodes are supported by a rigid substrate so the sensor structure does not change with contraction, pressure or expansion of the cooking oil samples.

The impedance value depends on the capacitance measurements from the sensor. The capacitance values can be affected by electric flux and fringing fields. When the distance of electrode separation is much smaller than the magnitude of the area in overlaps tooth, the capacitance between opposing teeth is due to electric flux and is not due to fringing field effect. However, since the border around two parallel plate electrodes with same distance separation and overlapping area is much smaller the perimeter around the teeth, in this case consider the fringing effect greater in interdigitated electrode. When the separation distance is in the same order as the height of the teeth, much of the capacitance will be as a result of the fringing field outside of the space directly between the interdigitated teeth. The density of electric flux changed in the sensor's surface attributed to the dielectric constant changes of cooking oil.

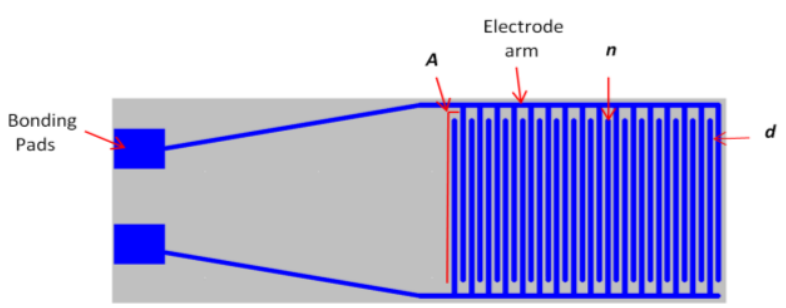

(a)

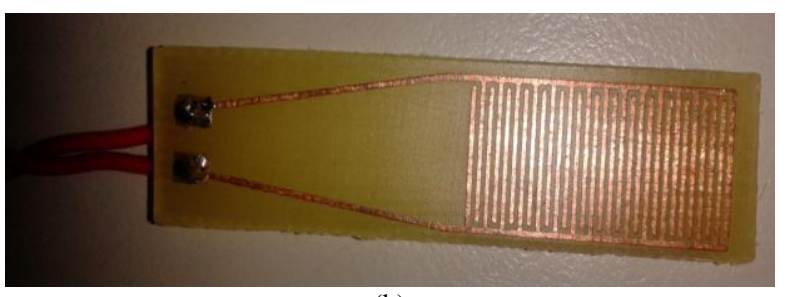

(b)

Fig. 2. Impedance sensing probe (a), schematic of the impedance sensor (b), photograph prototype of the sensor.

\section{Measuring the Oil Quality}

The TPC of each sample was examined using Testo (Cooking oil sensor 270 manufacturer by Testo). Then the impedance measurement for the samples was performed at $60^{\circ} \mathrm{C}$ temperature. Using the impedance sensing probe connected to a LCR meter with two parallel clips (HIOKI, 3532-50, Japan, frequency accuracy: < $\pm 0.005 \%$, measurable impedance range: $10.00 \mathrm{~m} \Omega \sim 200.00 \mathrm{~m} \Omega$ ), as shown in Fig. 3. The frequency range used was from $100 \mathrm{~Hz}$ to $100 \mathrm{kHz}$. The viscosity (mPa.s) of the samples was also measured using Vibro Viscometer (SV-10 Series, A\&D Company, Limited). Since the properties of the oil can be changed with the temperature of oil, all measurement was taken at a constant temperature. After each testing the sensing probe was cleaned with soft tissue before next testing. Each measurement was conducted five times.

\section{RESUlTS AND DisCUSSION}

\section{A. Oil Viscosity Measurements}

The viscosity of palm oil samples increased significantly as the heating hours increased. In the testing of oil viscosity the temperature was constant at $60^{\circ} \mathrm{C}$ to avoid the thermal movement among molecules [14]. The viscosity value of the unheated oil is $18.9 \mathrm{mPa}$.s while in the 40 heating hours the viscosity is $26.8 \mathrm{mPa}$.s as shown in Table I. These results may be explained by the fact that the increasing of saturation of the oil constituents [15]. Moreover, the increasing of viscosity is related to the polymer content. Polymerization also has been assigned to the construction of unwanted compounds. Additionally, the quality and palatability can be affected by the viscosity during the heating directly by influencing the oil absorption of the product [16].

\section{B. Total Polar Compounds Measurements}

The TPC increased significantly with prolonged heating time. It has been recommended that when the TPC is more than $24-27 \%$, the oil should be discarded [17]. The amount of polar compounds in fresh oil was $7.5 \%$ and reached to $27 \%$ after $40 \mathrm{~h}$ heating as shown in Table II. Changes in the polar compounds during heating were significantly of formed new compounds that have higher polarity such as diacylglycerides, triglycerides, and fatty acids [18]. These new compounds formed due to high temperature during heating as well as the presence of air and moisture.

TABLE I: The MEASuREMEnt Data of Viscosity AND Total PolaR COMPOUNDS

\begin{tabular}{ccc}
\hline \hline Oil samples & Viscosity mPa.s & TPC \% \\
\hline Nonheated & 18.9 & 7.5 \\
10 hours heating & 22.1 & 11 \\
20 hours heating & 22.9 & 16 \\
30 hours heating & 26 & 22.5 \\
40 hours heating & 26.8 & 27 \\
\hline \hline
\end{tabular}

\section{Oil Impedance Measurement}

As shown in Fig. 3, the impedance of the unheated oil samples as function of frequency has highest impedance values comparing to heated samples. While the 40 hours heated sample has the lowest impedance values. The variations of these results are possibly due to dipole content in the fat particularly the phospholipid [19]. Also, in the graph, impedance values decreased over the range of 
frequency $(100 \mathrm{~Hz}$ to $100 \mathrm{kHz})$. The dipole density and electric susceptibility increased, as the amount of the fat in the oil increased. This leads to the decrement of the impedance of the oil samples. We also could see in the figure shown, a clear difference of the impedance value of the oil samples at low frequency ranges. However, at high frequency all the impedance measurement values are overlapped. Significant correlation found in Fig. 4, the correlation between the impedance values with the total polar compounds at frequency $100 \mathrm{~Hz}$ with $r^{2}$ of -0.98472 .

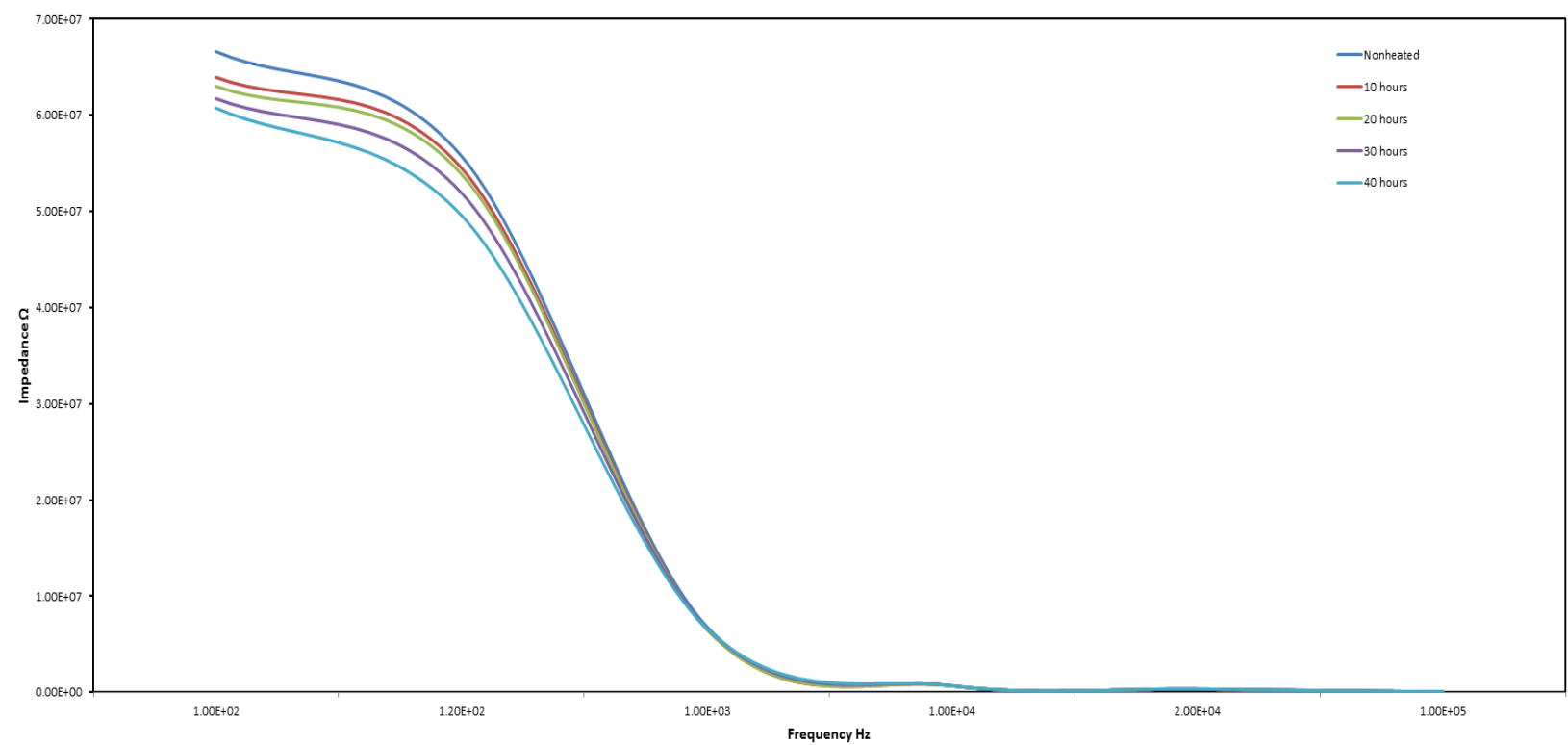

Fig. 3. Impedance of different heated oil samples across frequency between $100 \mathrm{~Hz}$ to $100 \mathrm{kHz}$.

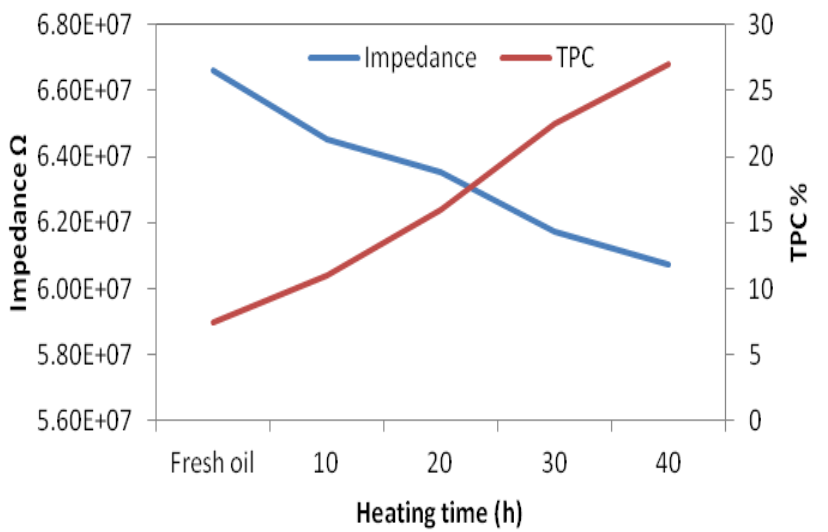

Fig. 4. The correlation of impedance and total polar compound of heated oil sample at $100 \mathrm{~Hz}$.

\section{CONCLUSION}

The result in this study shows a significant correlation between impedance value and TPC at different heating intervals (hours). Impedance spectroscopy method can be considered as an alternative method for measuring oil quality.

\section{ACKNOWLEDGMENT}

This study is funding by Prototype Research Grant Scheme, Ministry of Higher Education, and project number 5528400 .

\section{REFERENCES}

[1] W. L. Clark and G. W. Serbia, "Safety aspects of frying fats and oils," Food Technology, vol. 45, no. 2, pp. 84-89, 1991.

[2] B. Innawong, P. Mallikarjunan, and J. E. Marcy, "The determination of frying oil quality using a chemosensory system," LWT-Food Science and Technology, vol. 37, no. 1, pp. 35-41, 2004.
[3] M. Hein, H. Henning, and H. D. Isengard, "Determination of total polar parts with new methods for the quality survey of frying fats and oils," Talanta, vol. 47, no. 2, pp. 447-454, 1998.

[4] B. Innawong, P. Mallikarjunan, J. Irudayaraj, and J. E. Marcy, "The determination of frying oil quality using Fourier transform infrared attenuated total reflectance," LWT-Food Science and Technology, vol. 37, no. 1, pp. 23-28, 2004.

[5] F. T. Orthoefer, "Care of food service frying oils," Journal of the American Oil Chemists' Society, vol. 65, no. 9, pp. 1417-1419, 1988.

[6] K. S. Lee, K. Lee, V. Lau, K. Shin, and B. K. Ju, "SWNT sensors for monitoring the oxidation of edible oils," World Acad. Sci. Eng. Tech, vol. 74, pp. 385-388, 2011.

[7] R. G. Moreira, M. E. Castell-Perez, and M. A. Barrufet, "Frying oil characteristics," Deep-Fat Frying Fundamentals and Applications, Gaithersburg, ML: Aspen Publishers Inc., pp. 33-74, 1999.

[8] N. Frega, M. Mozzon, and G. Lercker, "Effects of free fatty acids on oxidative stability of vegetable oil," Journal of the American Oil Chemists' Society, vol. 76, no. 3, pp. 325-329, 1999.

[9] P. J. White, "Methods for measuring changes in deep-fat frying oils," Food Technology, vol. 45, no. 2, pp. 75-80, 1991

[10] N. Gotoh, and S. Wada, "The importance of peroxide value in assessing food quality and food safety," Journal of the American Oil Chemists' Society, vol. 83, no. 5, pp. 473-474, 2006.

[11] B. Gil, Y. J. Cho, and S. H. Yoon, "Rapid determination of polar compounds in frying fats and oils using image analysis," LWT-Food Science and Technology, vol. 37, no. 6, pp. 657-661, 2004.

[12] A. Cert, W. Moreda, and M. C. Pérez-Camino, "Chromatographic analysis of minor constituents in vegetable oils," Journal of Chromatography A, vol. 881, no. 1, pp. 131-148, 2000.

[13] N. Vlachos, Y. Skopelitis, M. Psaroudaki, V. Konstantinidou, A. Chatzilazarou, and E. Tegou, "Applications of Fourier transform-infrared spectroscopy to edible oils," Analytica Chimica Acta, vol. 573, pp. 459-465, 2006.

[14] R. Kahn, D. Stehli, L. S. Wei, M. P. Steinberg, and N. Yamashita, "Activity and mobility of water in sweetened concentrated dislodged soy beverages and their rheological properties," Journal of Food Science, vol. 55, no. 2, pp. 537-542, 1990 .

[15] J. C. O. Santos, I. M. G. Santos, and A. G. Souza, "Effect of heating and cooling on rheological parameters of edible vegetable oils," Journal of Food Engineering, vol. 67, no. 4, pp. 401-405, 2005.

[16] E. Kress-Rogers, P. N. Gillatt, and J. B. Rossell, "Development and evaluation of a novel sensor for the in situ assessment of frying oil quality," Food Control, vol. 1, no. 3, pp. 163-178, 1990. 
[17] D. Firestone, "Worldwide regulation of frying fats and oils," Inform. vol. 4, pp. 1366-1371, 1993.

[18] M. D. C. Flores-Álvarez, E. F. Molina - Hernández, J. C. Hernández - Raya, and M. E. Sosa - Morales, "The effect of food type (fish nuggets or french fries) on oil blend degradation during repeated frying," Journal of Food Science, vol. 77, no. 11, pp. c1136-c1143, 2012.

[19] S. Aditama, "Dielectric properties of palm oils as liquid insulating materials: effects of fat content," in Proc.2005 International Symposium on IEEE, Electrical Insulating Materials, vol. 1, pp. 91-94, June 2005

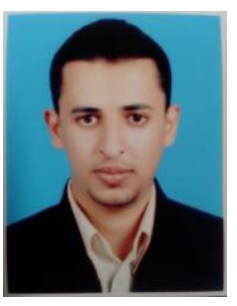

Alfadhl Yahya Khaled is from Yemen. He received his Undergraduate Degree in Engineering (Honours) Electronics majoring in Bio-Instrumentation, Faculty of Engineering, Multimedia University, Melaka, Malaysia in 2012.

$\mathrm{He}$ is currently studying Master of Science. Agricultural Mechanization and Automation in Faculty of Engineering, Universiti Putra Malaysia, Selangor, Malaysia.

Mr. Yahya is in the development and Evaluation of an Impedance Spectroscopy Sensor to Assess Cooking Oil Quality. Mr. Yahya awarded a silver middle from i-ENVEX 2013.

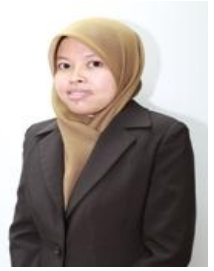

Samsuzana Abd Aziz is from Malaysia. She received Bachelor of Engineering in Electrical Telecommunication from Universiti Teknologi Malaysia in 2002 and then pursued her Master and Ph.D. in Agricultural Engineering at Iowa State University, USA. Currently, she is in the Head Department of Biological \& Agricultural Engineering, Universiti Putra Malaysia and her research interest are mainly on Agricultural and Biosystems Instrumentation, and GIS. Dr. Samsuzana is the vice president of MSAE treasurer of IEEE GOLD Affinity Group and member of ASABE, and BEM. She had received many international and national awards for her respective research work.

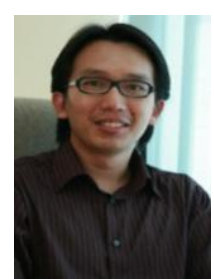

Fakhrul Zaman Rokhani is from Malaysia. He received his B. Eng. with Honor in ElectricalMechatronics Engineering, Universiti Teknologi Malaysia, M.Sc. in Electrical Engineering, University of Minnesota, USA, and Ph.D. in Electrical Engineering, University of Minnesota, USA.

$\mathrm{He}$ is currently a lecturer in department of Computer and Communication System, Universiti Putra Malaysia. And his research interest are mainly on Nano-scale VLSI design and sensor design. Dr. Fakhrul is a member of Institute of Electrical and Electronics Engineers (MIEEE) and member of International Association of engineers (IAENG). He had received many international and national awards for his respective research work. 